\title{
Risk Factors of Measles Outbreak Among Students of Mizan-Tepi University, Tepi Campus, Southwest Ethiopia
}

\author{
Fekede W/Kidan (1) \\ Dawit Getachew (D) \\ Besufekad Mekonnen $\mathbb{D}^{2}$ \\ Workineh Woldeselassie \\ Hammeso (iD ${ }^{3}$ \\ 'School of Public Health Department of \\ Epidemiology and Biostatistics, Collage of \\ Medicine and Health Science, Mizan-Tepi \\ University, Mizan-Aman, Ethiopia; \\ ${ }^{2}$ School of Public Health Department of \\ Public Health, Collage of Medicine and \\ Health Science, Mizan-Tepi University, \\ Mizan-Aman, Ethiopia; ${ }^{3}$ School of \\ Pharmacy, Department Pharmacology \\ and Pharmaceutical Chemistry College of \\ Medicine and Health Sciences, Mizan-Tepi \\ University, Mizan-Aman, Ethiopia
}

This article was published in the following Dove Press journal: Infection and Drug Resistance

\begin{abstract}
Background: Measles is a serious respiratory disease that is spread easily through coughing and sneezing of the measles virus for which humans are the only reservoir. Even though prevention and elimination strategies had been implemented, the outbreaks of measles infection quietly occur in different parts of the world. As of November 2019 a suspected measles outbreak was reported from Tepi campus student's clinic. We investigated the outbreak to determine its possible sources, control measures and identify associated risk factors among students of Mizan-Tepi University.
\end{abstract}

Methods: A facility based unmatched case-control study was conducted. An interviewer administered questionnaire was used to collect the data. Data were cleaned and entered to Epi-info7 and analyzed using SPSS-20. A logistic regression analysis was conducted to identify risk factors associated with measles outbreak at a p-value $\leq 0.05$.

Results: A total of 40 measles cases were reported during the investigation. The probable source of the outbreak was an index case who had a travel history to a district with the measles epidemic. Five samples were collected for confirmation of the diagnosis. No measles-related deaths were reported. The major risk factors for measles infection in MizanTepi University were being unvaccinated $[\mathrm{AOR}=5.21,95 \%$ CI $(1.938,12.058)]$, being female $[\mathrm{AOR}=4.21,95 \% \mathrm{CI}(1.426,11.182)]$, age group of $18-20[\mathrm{AOR}=0.123,95 \% \mathrm{CI}$ $(0.041,0.37)]$ and having a contact history $[\mathrm{AOR}=0.149,95 \% \mathrm{CI}(0.041,0.544)]$.

Conclusion: The findings of the present investigation indicated that being unvaccinated and having a contact history with confirmed or suspected cases increased the risk of measles infection. Reduction in the level of protective antibodies over time may accelerate transmission of measles in the campus. Strengthening case-based surveillance and supplemental measles vaccination are imperative.

Keywords: measles outbreak, Mizan-Tepi University, risk factors, students

\section{Introduction}

Measles is a serious respiratory disease that is spread easily through coughing and sneezing of the measles virus, for which humans are the only reservoir. ${ }^{1}$ It is a member of the genus Morbillivirus of the Paramyxoviridae family. The average incubation period for measles is 14 days, with a range of 7-21 days. An infected person with measles is contagious from four days before to four days after the rash appears and it has a short survival time $\left(<2\right.$ hours) in air or on objects and surfaces. ${ }^{2-4}$

People with the measles infection often have a prodromal fever, conjunctivitis, coryza, cough and the presence of Koplik spots (reddish spots with a white center)
Correspondence: Workineh Woldeselassie Hammeso

P.o. Box 260, Mizan-Teferi, Ethiopia

Tel +251912183453

Email workinehws@yahoo.com
Infection and Drug Resistance 2021:14 963-970 
on the buccal mucosa. The frequency of complications varies in different parts of the world. In industrialized countries, complications occur in around $10-15 \%$ of cases whereas in developing countries; up to $75 \%$ of cases may have one or more complications. These include pneumonia, diarrhea, and encephalitis and these complications could occur in up to $30 \%$ of persons depending on age and predisposing conditions, such as young age, malnutrition and immune-compromising conditions. They are also the major causes and contributing factors to the high case-fatality rate. Measles infection can also lead to lifelong disabilities, including blindness, brain damage and deafness. $^{1,4,5}$

Worldwide more than 140,000 peoples died from measles in 2018; it has decreased from 535,600 deaths in 2000. In Africa, 1,759,000 measles cases and 52,600 deaths occurred and it ranks among the top ten-causes of childhood mortality. According to a WHO report; there are increments in case reports as compared to previous years; a 10-fold increase in measles case report were reported from Africa whereas there was a 2-fold increase in Europe. The highest reports were seen in the democratic republic of Congo 250,000 cases were reported by the year 2019, the outbreak has affected all 26 provinces of the country and 3559 deaths were reported from a total of 179,477 suspected cases, also in Somalia measles is one of the leading cause of child mortality and morbidity. In Ethiopia the measles outbreak is still ongoing with a total of 8,201 suspected measles cases reported by the WHO until the end of September, 2019 from Oromia (4610), Somali (2340), Amhara (703) and Afar (548) regions. From all cases $25.5 \%$ were within the age group of 15-44 years, from all measles cases seventy-two percent of the reported measles cases were not previously vaccinated. $^{1,6,7}$

Measles infection and outbreak is one of the most serious public health problems in different regions of Ethiopia. It is estimated that about 66,719 confirmed cases were reported between the year 2006 and 2016 in Ethiopia. $^{8}$ The country is executing diverse approaches in preventing and controlling of the measles infection. Even though there were different strategies to overcome the incidence of measles infection a seasonal pattern (mostly December to February) of measles outbreaks occurred in Ethiopia starting from 2010 and it becomes higher in 2012 up to 2014 . $^{8,9}$

Several studies have highlighted that measles outbreak occurrences were associated with a spectrum of factors, from an unvaccinated population, travel history, contact history, many low-income country's socioeconomic and demographic factors, factors related to the student's immunological status, sex, and factors related to overcrowding as pertinent and definitely central factors contributing to contracting the measles infection during an outbreak. ${ }^{9-13}$ The main aim of this study is to investigate the outbreak and identify associated risk factors with a measles infection.

\section{Methods and Materials Study Area and Period}

An institutional based unmatched case control study was conducted for the outbreak investigation from November 5 to November 29, 2019, in Mizan-Tepi University Tepi Campus which is found in Tepi Town, Sheka Zone, southwest Ethiopia. It is situated $578 \mathrm{~km}$ from Addis Ababa (the capital city of the country). Tepi campus is one of the subdivisions of the main campus of Mizan-Tepi University. It has an engineering and a natural and computational science faculty with a total of 5,572 students.

\section{Sample Size and Sampling Technique}

A total of 120 samples, 40 available cases and 80 comparable controls were included from the outbreak affected students. Enrolment of cases and controls; randomly selected students who were diagnosed as having a measles infection and an online list were included in the study as cases. Controls were students within the same dormitory as cases that did not have a measles infection during the study period. Two randomly selected controls for each case were selected from the dormitory until the sample size was reached. ${ }^{14}$

\section{Data Collection Tools Procedure and Personnel}

Data were collected from all eligible study participants by structured standard questionnaire using a WHO standard case definitions criteria through active case search and adapted from previously conducted studies and customized to fit with the current study setup. Three data collectors and deployed outbreak investigation team members, through face to face interviews, were involved in the data collection procedure. The questionnaire involves socio-demographic characteristics, epidemiologic and medical history, date of onsets, sign and symptoms, travel history, knowledge about measles infection and others. The questionnaire was 
translated to the Amharic language by a person who speaks both languages and has a knowledge of the subject matter.

\section{Data Quality Control}

Data quality was ensured during the collection, coding, entry and analysis. The data collectors and supervisors underwent appropriate orientation. Close supervision was done by the principal investigators and supervisors throughout the data collection period. Collected data was checked for completeness and consistency and double data entry was done to check for any missing values.

\section{Data Processing and Analysis}

Data were cleaned and entered to Epi-info7 and imported to SPSS-20 for further analysis. After checking all assumptions of logistic regression, bivariable logistic regression was carried out to select candidates for multivariate logistic regression analysis with p-value $<0.20$ at $95 \%$ confidence level. ${ }^{15}$ Then, candidate variables were entered in to multivariable logistic regression models using backward method to identify the statistically significant factors for measles infection by controlling possible confounders. Descriptive analysis was conducted to generate percentages and figures whereas odds ratios with $95 \%$ confidence intervals were computed to compare risk factors among cases and controls.

\section{Ethical Considerations}

Ethical assurance was obtained from Mizan-Tepi University College of Medicine and Health Sciences institutional health research ethics review committee with approval number CMHS/0873/42/2019. The study participants were informed about the occurrence of the outbreak, the purpose and benefit of the study to be carried out. Verbal informed consent was approved by the research ethics committee. This is due to a study participant having developed conjunctivitis, and coryza, they had poor eyesight and trouble reading the form written in twelve-point type. The act was formally witnessed by a nearby clinician. Moreover, this study was conducted in accordance with the Declaration of Helsinki.

\section{Result}

A total of 40 measles cases, with no deaths, were reported during the investigation. An index male case was a 21 years old, first year student who presented with sudden onset of rash, cough, fever and conjunctivitis. He had a travel history to Gamo Gofa Zone SNNPR to meet his family, where a measles outbreak occurred before, three weeks ago, among children. All of the five specimens that were collected from the 40 cases reported on the line list were measles IgM positive. The mean age of the students was 20.09 years ( $\mathrm{SD} \pm 1.152$ years). Among all measles cases the majority $60 \%$ (24) were males and almost half of the cases and controls 52.5\% (21) and 48.7\% (39) respectively came from the Amhara region (Table 1).

From the symptom onset date of the index case-person (November 5, 2019) to that of the last case-person (29 November, 2019), the outbreak lasted 25 days. Measles transmission from the index case to other campus student cases occurred at the dormitory, campus dining halls, in classrooms, and at several campus collective

Table I Socio-Demographic Characteristics of Students in Tepi Campus, November, 2019

\begin{tabular}{|c|c|c|c|c|}
\hline Variables & $\begin{array}{l}\text { Cases } \\
N=40\end{array}$ & $\begin{array}{l}\text { Controls } \\
\mathbf{N}=\mathbf{8 0}\end{array}$ & COR in $95 \% \mathrm{Cl}$ & P-value \\
\hline \multicolumn{5}{|l|}{ Sex } \\
\hline Female & $16(40 \%)$ & $22(27.5 \%)$ & I & 0.167 \\
\hline Male & $24(60 \%)$ & $58(725 \%)$ & I.758(0.255, I.267) & \\
\hline \multicolumn{5}{|l|}{ Age } \\
\hline $18-20$ & $19(47.5 \%)$ & $66(82.5 \%)$ & I & $0.000 *$ \\
\hline $21-23$ & $2 \mathrm{I}(52.5 \%)$ & $14(17.5 \%)$ & $0.192(0.82,0.448)$ & \\
\hline \multicolumn{5}{|l|}{ Religion } \\
\hline Muslim & $4(10 \%)$ & $\mathrm{II}(13.8 \%)$ & & \\
\hline Orthodox & $31(77.5 \%)$ & $47(58.8 \%)$ & & \\
\hline Protestant & $5(12.5 \%)$ & $20(25 \%)$ & & \\
\hline Others & $0(0.0 \%)$ & $2(2.5 \%)$ & & \\
\hline
\end{tabular}

Note: ${ }^{*} \mathrm{P}<0.05$.

Abbreviation: COR, crude odds ratio. 


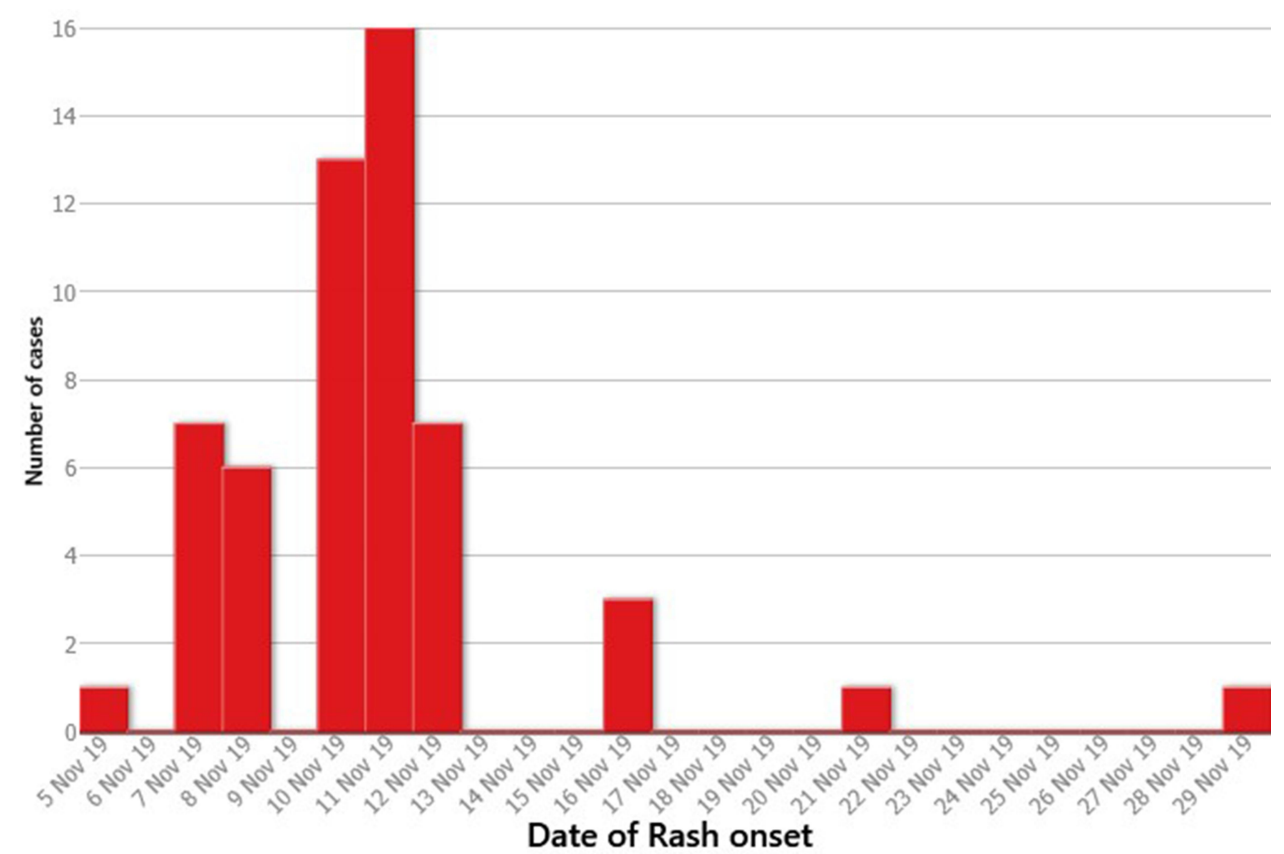

Figure I Measles cases reported by date of onset Mizan-Tepi University, Tepi Campus, southwest Ethiopia, 2019.

occasions and there was no transmission out of the university (Figure 1).

A total sample of 120 students, 40 measles cases and 80 controls, were included in the study making a $100 \%$ response rate. From the total $16(40 \%)$ of the cases and 22 (27.5\%) of the controls were female students. The mean ages of cases were $20.6 \pm 1.25$ SD years while the mean age of controls were 19.8 \pm 1.005 SD years (Table 2).

\section{Vaccination Status, Knowledge and Other Characteristics of the Participants}

The majority of the students, 18 (45\%) and $65(81.2 \%)$, among cases and controls had vaccination history respectively. By contrast, 22 (55\%) cases and 15 (18.8\%) controls had never been vaccinated. On the other hand 30 (75\%) cases and $72(90 \%)$ controls had no contact history with infected measles patients. Regarding the knowledge level of the students about measles infection 15 (37.5\%) cases and $20(25 \%)$ controls had poor knowledge about measles infection. Similarly, $13(32.5 \%)$ of the cases and $12(15 \%)$ controls described the presence of a measles infected student within the dormitory (Table 3).

In bivariate analysis, measles infection was associated with the sex of the student, age, vaccination status, contact history, knowledge level, previous measles infection and presence of an infected person in the dormitory (Table 2).
In multivariable logistic regression analysis, age, sex, contact history and vaccination status were independently associated with the measles outbreak. Students in the age group of $18-20$ years were $87.5 \%$ less likely to have a measles infection than those who were $21-23$ years $[\mathrm{AOR}=0.123,95 \%$ CI $(0.041,0.37)]$. Another factor that showed an association of measles infection was the sex of the students. Female students were 4 times more likely to develop measles infection than male students $[\mathrm{AOR}=4.21,95 \% \mathrm{CI}(1.426,11.182)]$. Having a history of contact with an infected student was also independently associated with the outbreak [AOR $=0.149,95 \% \mathrm{CI}$ $(0.041,0.544)]$. The other strong predictor of measles infection was vaccination status, recording an odds ratio of 5.21 (95\% CI $(1.938,12.058))$, which indicates unvaccinated students were almost 5 times more likely to have a measles infection than vaccinated students.

\section{Discussion}

On November 7, 2019 Mizan-Tepi University and Sheka Zonal health department reported to south nation's nationalities and peoples regional Health Bureau a suspected outbreak of measles among Mizan-Tepi University, Tepi Campus students. Then samples were collected and sent to the Ethiopian Public Health Institute for confirmation of the diagnosis. The results of these samples were positive for measles-specific-IgM antibodies. In response to the 
Table 2 Bivariate Analysis for Different Exposure of Measles Outbreak in Tepi Campus, Southwest Ethiopia, 2019

\begin{tabular}{|c|c|c|c|c|}
\hline Variables & $\begin{array}{l}\text { Cases } \\
N=40\end{array}$ & $\begin{array}{l}\text { Controls } \\
\mathbf{N}=\mathbf{8 0}\end{array}$ & COR in $95 \% \mathrm{Cl}$ & P-value \\
\hline \multicolumn{5}{|l|}{ Vaccination status } \\
\hline Not vaccinated & $22(55 \%)$ & $15(18.8 \%)$ & I & $0.000^{*}$ \\
\hline Vaccinated & $18(45 \%)$ & $65(81.2 \%)$ & $5.29(2.29, \mid 2.251)$ & \\
\hline \multicolumn{5}{|l|}{ Contact history } \\
\hline No & $30(75 \%)$ & $72(90 \%)$ & 1 & $0.035^{*}$ \\
\hline Yes & $10(25 \%)$ & $8(10 \%)$ & $0.33(0.120,0.927)$ & \\
\hline \multicolumn{5}{|l|}{ Knowledge } \\
\hline Poor knowledge & $15(37.5 \%)$ & $20(25 \%)$ & 1 & 0.158 \\
\hline Good knowledge & $25(62.5 \%)$ & $60(75 \%)$ & I.8(0.796,4.07I) & \\
\hline \multicolumn{5}{|c|}{ Infected person in the dormitory } \\
\hline No & $27(67.5 \%)$ & $68(85 \%)$ & 1 & \\
\hline Yes & $13(32.5 \%)$ & $12(15 \%)$ & $0.367(0.149,0.904)$ & $0.029 *$ \\
\hline \multicolumn{5}{|c|}{ No. of Studt. in dormitory } \\
\hline$\leq 4$ & $5(\mid 2.5 \%)$ & $15(18.8 \%)$ & 1 & \\
\hline $5-7$ & $26(65.5 \%)$ & $62(77.5 \%)$ & $0.795(0.262,2.414)$ & 0.685 \\
\hline$\geq 8$ & $9(22.5 \%)$ & $3(3.8 \%)$ & $0.777(0.021,1.110)$ & 0.991 \\
\hline \multicolumn{5}{|c|}{ Previous measles infection } \\
\hline No & $34(85 \%)$ & $74(92.5 \%)$ & I & \\
\hline Yes & $6(15 \%)$ & $6(7.5 \%)$ & $0.459(0.138,1.529)$ & 0.205 \\
\hline
\end{tabular}

Note: $* \mathrm{P}<0.05$.

Abbreviation: COR, crude odds ratio.

confirmed measles case an organized team of investigators was sent to Sheka Zone, Tepi Campus to investigate this outbreak. This study suggests that a broad range of multiple risk factors were significantly associated with a measles infection, those are; sex, age, being unvaccinated and having a contact history with confirmed or suspected cases increased the risk of measles infection.

In this outbreak investigation, it was observed that there were no measles related deaths despite the fact that case fatality from measles is estimated to be $3-5 \%$ in developing countries and may reach more than $10 \%$ when occurring in nutritionally deprived areas. ${ }^{16}$ This finding was in-line with similar studies conducted in rural districts of Ethiopia in which the majority of the cases were adults aged $\geq 15$ years with no deaths. ${ }^{17}$ This could be due to an effective case management following an early detection of the outbreak and because of the fact that all of the cases were adults. In the current outbreak being female was found to be an independent factor to develop measles infection. This finding contrasts with the results of other studies which showed no significant relationship between the sex of the students. ${ }^{18-20}$ The difference may be due to variation in sample size, research methodology and may be time difference; those studies were conducted a long time ago.

In our analysis, we found that those aged between 1820 were almost $84 \%$ less likely to develop a measles infection as compared to students whose age is $21-23$ during the outbreak. These data are comparable with previous surveys where medical students aged 19-25 years old showed better protection against measles as compared to those aged $29-35 .^{21}$ This may be attributed to a reduction in the level of protective antibodies and the protection induced by a measles vaccination persist at least until early adulthood. ${ }^{22}$

A previous study has shown that measles usually occurred in young unvaccinated children. ${ }^{23}$ However, the measles outbreak in this study area mainly involved adults aged between 18 and 23years. Surprisingly, 18 (45\%) and 65 (81.2\%) among cases and controls had a vaccination history, respectively.The finding of our study is comparable with a study done in China where (73.33\%) infected patients had received a single dose measles vaccination during their childhood. ${ }^{24}$ This finding suggests that the 
Table 3 Multivariate Analysis of Predictors of Measles Outbreak, Among Students of Tepi Campus, Southwest Ethiopia, 2019

\begin{tabular}{|c|c|c|c|c|c|}
\hline Variables & $\begin{array}{l}\text { Cases } \\
N=40\end{array}$ & $\begin{array}{l}\text { Controls } \\
\mathbf{N}=\mathbf{8 0}\end{array}$ & COR in $95 \% \mathrm{Cl}$ & AOR in $95 \% \mathrm{Cl}$ & P-value \\
\hline \multicolumn{6}{|l|}{ Vaccination status } \\
\hline Not vaccinated & $22(55 \%)$ & $15(18.8 \%)$ & I & I & \\
\hline Vaccinated & $18(45 \%)$ & $65(81.2 \%)$ & $5.29(2.29,12.25 \mathrm{I})$ & $5.149(1.938,12.058)$ & $0.001 *$ \\
\hline \multicolumn{6}{|c|}{ Infected person in the dormitory } \\
\hline No & $27(67.5 \%)$ & $68(85 \%)$ & I & I & \\
\hline Yes & $13(32.5 \%)$ & $12(15 \%)$ & $0.367(0.149,0.904)$ & $0.591(0.156,2.234)$ & 0.438 \\
\hline \multicolumn{6}{|l|}{ Knowledge } \\
\hline Poor knowledge & $15(37.5 \%)$ & $20(25 \%)$ & I & I & \\
\hline Good knowledge & $25(62.5 \%)$ & $60(75 \%)$ & I.8(0.796,4.07I) & $2.033(0.683,6.050)$ & 0.202 \\
\hline \multicolumn{6}{|l|}{ Contact history } \\
\hline No & $30(75 \%)$ & $72(90 \%)$ & I & I & \\
\hline Yes & $10(25 \%)$ & $8(10 \%)$ & $0.33(0.120,0.927)$ & $0.149(0.041,0.544)$ & $0.004 *$ \\
\hline \multicolumn{6}{|c|}{ Previous measles infection } \\
\hline No & $34(85 \%)$ & $74(92.5 \%)$ & I & I & \\
\hline Yes & $6(15 \%)$ & $6(7.5 \%)$ & $0.459(0.138,1.529)$ & $0.348(0.074, I .644)$ & 0.183 \\
\hline \multicolumn{6}{|l|}{ Sex } \\
\hline Female & $16(40 \%)$ & $22(27.5 \%)$ & I & I & \\
\hline Male & $24(60 \%)$ & $58(725 \%)$ & I.758(0.255,I.267) & $4.21(1.426, I I .182)$ & $0.009 *$ \\
\hline \multicolumn{6}{|l|}{ Age } \\
\hline $18-20$ & $19(47.5 \%)$ & $66(82.5 \%)$ & I & I & \\
\hline $21-23$ & $21(52.5 \%)$ & $14(\mid 7.5 \%)$ & $0.192(0.82,0.448)$ & $0.123(0.041,0.370)$ & $0.000 *$ \\
\hline
\end{tabular}

Note: $* \mathrm{P}<0.05$.

Abbreviations: COR, crude odds ratio; AOR, adjusted odds ratio.

level of protection provided by a single measles immunization may drop to baseline and cease to protect against the disease. ${ }^{24}$ Furthermore, reports on epidemiologic data also showed that an increasing proportion of measles outbreak cases continue to occur in most parts of the country with nearly $70 \%$ of the reported cases being $\geq 15$ years. ${ }^{25-29}$ This might be due to the lack of a policy agreement on vaccinating broader age groups, limited supplies of vaccine and accumulation of unvaccinated adults in the community as they were not targeted for the immunization program unlike that of children under five years.

In the current study, previously unvaccinated students had a 5 times higher risk of acquiring a measles infection as compared to vaccinated students. This result is consistent with another study which found that vaccinated individuals had less risk to acquire a measles infection. ${ }^{11,14,20,30,32}$ This finding was in contrast with the study conducted in Fort Lewis College which showed that vaccination status did not have a significant association with a measles outbreak. ${ }^{32}$ This could be attributed to the fact that measles immunization may be imperfect to produce whole immunity. ${ }^{28}$ Additionally, this finding could be subjected to recall bias as some study participants lack immunization cards showing doses given; age at which vaccine is administered, the quality of vaccine and the adequacy of the cold chain may influence the susceptible status of individuals.

On the other hand, students who had no previous contact history with an infected person had $79 \%$ less risk of acquiring measles infection as compared to those who had contact history. This finding is consistent with a study conducted in Amhara and Somali regions of Ethiopia. ${ }^{14,31}$ This was attributable to the fact that most students who had frequent contact within the campus might influence increased virus transmission to the susceptible hosts since measles is a highly contagious disease transmitted by respiratory droplet or airborne spread.

Although knowledge about prevention and transmission of measles and previous measles infection have 
been shown to play a significant role in a measles outbreak, these variables did not shows significant association with the outbreak. ${ }^{33}$

\section{Limitation}

Data was obtained directly from the study participants, recall bias could have been a problem to the current study. And the sample size was small, sointerpretation should be with caution.

\section{Conclusion}

The findings of the present investigation indicated that being unvaccinated and having contact history with confirmed or suspected cases increased the risk of measles infection. More importantly this outbreak investigation revealed occurrence of measles in the higher age group due to either non-vaccination or the reduction in the immune-status over time, these may accelerate transmission of measles in the campus. There should be a laboratory evaluation of protective measles IgG levels and mandatory vaccination for measles should be imperative.

\section{Abbreviations}

CDC, Central Disease Control; EDHS, Ethiopian Demographic and Health Survey; EPHI, Ethiopia Public Health Institution; EPI, expanded program for immunization; MCV, measles-containing vaccine; SIAs, supplemental immunization activities; SNNP, Southern Nations and Nationality of Peoples; UNICEF, United Nations Children's Fund; VPD, vaccines preventable disease; WHO, World Health Organization.

\section{Data Sharing Statement}

The data that support the findings of this study are available from the corresponding author upon reasonable request.

\section{Acknowledgments}

The authors would like to thank Mizan-Tepi University, Tepi Hospital, and the Tepi campus student's clinic team. Thanks are extended to EPHI for help in diagnosis of five samples.

\section{Author Contributions}

All authors made a significant contribution to the work reported, whether that is in the conception, study design, execution, acquisition of data, analysis and interpretation, or in all these areas; took part in drafting, revising or critically reviewing the article; gave final approval of the version to be published; have agreed on the journal to which the article has been submitted; and agree to be accountable for all aspects of the work.

\section{Disclosure}

The authors declare that they have no competing interests.

\section{References}

1. WHO. World Health Organization Regional Office for Africa Measles SIAs Field Guide. WHO; 2006.

2. Ethiopian Health and Nutrition Research Institute. Guideline on Measles Surveillance and Outbreak Management. 3rd ed. Addis Ababa: EHNRI; 2012.

3. Arizona Department of Health Services. 2016. Measles Surveillance Toolkit for Healthcare Settings. Department of Health Services Office of Infectious Disease Services. editor. Arizona: ADHS.

4. WHO. 2018. Measles. Vaccine-Preventable Diseases Surveillance Standards. editor. Geneva: WHO.

5. WHO. WHO Guidelines for Epidemic Preparedness and Response to Measles Outbreaks. Geneva, Switzerland; 1999.

6. WHO. Fact Sheet of Measles Outbreak. Geneva: WHO; 2019.

7. WHO. Weekly Bulletin on Outbreak and Other Emergencies. Geneva, Swizerland: WHO; 2019.

8. Teklay K, Desta ETL, Wayess JD, Masresha BG. Measles epidemiology in Ethiopia from 2006-2016: predictors of high measles incidence from surveillance data analysis. $J$ Immunol Sci. 2018;018:122-129.

9. Akalu HB. Review on measles situation in ethiopia; past and present J Trop Dis. 2015;4(193):4.

10. Mengistie Kassahun Tariku SWM. Measles outbreak investigation in Artuma Fursi Woreda, Oromia Zone, Amhara Region, Ethiopia, 2018: a case control study. BMC Res Notes. 2019;12:765.

11. Pomerai KW, Mudyiradima RF, Gombe NT; Kufakwanguzvarova W Pomerai RFMaNTG. Measles outbreak investigation in Zaka, Masvingo Province, Zimbabwe, 2010. BMC Res Notes. 2012;5:687. doi:10.1186/1756-0500-5-687

12. Soo J, Kim R, Choi JS. Factors Influencing University nursing students' measles vaccination rate during a community measles outbreak. Asian Nurs Res. 2015;10(2016):56-61.

13. Bayu Begashaw Bekele TL, Daniel A, Kumalo A, Yimam H, Lamaro T. Determinants of Measles Recurrent Outbreak in South West Ethiopia: an Obstacle for Implementation of Infectious Disease Eradication in the Country. EC MICROBIOL. 2018;14(10):699-706.

14. Abadi Girmay AFD. Being unvaccinated and having a contact history increased the risk of measles infection during an outbreak: a finding from measles outbreak investigation in rural district of Ethiopia. BMC Infect Dis. 2019;19:345.

15. Swati Bajaj PB. Neha Singh Measles Outbreak in Adults: a Changing Epidemiological Pattern. Med J Dr DY Patil Univ. 2017;10:447-452. doi:10.4103/MJDRDYPU.MJDRDYPU_43_17

16. Guideline on Measles Surveillance and Outbreak Management. 3rd ed. Addis Ababa, Ethiopia: EHNRI;2012.

17. Girmay A, Dadi AF. Being unvaccinated and having a contact history increased the risk of measles infection during an outbreak: a finding from measles outbreak investigation in rural district of Ethiopia. BMC Infect Dis. 2019;19:345.

18. Jin $\mathrm{Y}$, Ma H, Zhang L, et al. Measles outbreak on a college campus transmitted through internet cafe's. J Infect Dis. 2011;204:S471S475. doi:10.1093/infdis/jir069 
19. Jagar Jasem KM, Adnan Nawar KM, Islam M. Epidemiological analysis of measles and evaluation of measles surveillance system performance in Iraq, 2005-2010. Elsevier Int J Infect Dis. 2012;16: e166-e171. doi:10.1016/j.ijid.2011.11.002

20. José E, Hagan YT, Sarankhuu A, et al. Risk factors for measles virus infection among adults during a large outbreak in postelimination era in Mongolia, 2015. J Infect Dis. 2017;216(1187):95.

21. Coppeta L, Pietroiusti A, Lieto P, et al. Measles immunity in an Italian teaching hospital. Occup Med (Chic Ill). 2019;69 (2):143-145. doi:10.1093/occmed/kqy132

22. Coppeta L, Somma G, Di Giampaolo L, et al. Persistence of antibodies for measles among vaccinated medical students in Italy. Infect Dis. 2020;30:1-3.

23. Ma C, Hao L, Zhang Y, et al. Monitoring progress towards the elimination of measles in China: an analysis of measles surveillance data. Bull World Health Organ. 2014;92(5):340-347. doi:10.2471/ BLT.13.130195

24. Zhang Z, Zhao Y, Yang L, et al. Measles outbreak among previously immunized adult healthcare workers, China, 2015. Can J Infect Dis Med Microbiol. 2016;2016:1-6. doi:10.1155/2016/1742530

25. Paul A, SF G, Lopman BA, et al. Factors associated with measles transmission in the United States during the postelimination era. JAMA Pediatr. 2019;174(1):56-62.

26. Pedro Plans NT, Godoy P, Jane M. Lack of herd immunity against measles in individuals aged $<35$ years could explain re-emergence of measles in Catalonia (Spain). Int $J$ Infect Dis. 2014;18:81-83. doi:10.1016/j.ijid.2013.09.015
27. National EPI. Comprehensive Multi-Year Plan 2016-2020. Ethiopia, Addis Ababa: FMoH; 2015.

28. Measles reporting and surveillance guidelines. Washington State Department of Health: 2014.

29. Expanded Programme on Immunization Annual Report, Ethiopia. 2014.

30. Rivadeneira MF. Role of health determinants in a measles outbreak in Ecuador: a case-control study with aggregated data. BMC Public Health. 2018;2018:18:269.

31. Abibakar Sheikaden Ismail MAA, Abdikarim AA, Yusuf AA. Risk factors for measles outbreak: an unmatched case control study in Kabridahar District, Somali Regional State, Ethiopia. Am J Epidemiol Infect Dis. 2018;7(1):1-5.

32. Hersi BS, Markowitz LE, Hoffinan RE, et al. A measles outbreak at a College with a prematriculation immunization requirement. $\mathrm{Am}$ J Public Health. 1991;81:3.

33. Tariku MK, Misikir SW. Measles outbreak investigation in Artuma Fursi Woreda, Oromia Zone, Amhara Region, Ethiopia, 2018: a case control study. BMC Res Notes. 2019;12:765.
Infection and Drug Resistance

\section{Publish your work in this journal}

Infection and Drug Resistance is an international, peer-reviewed openaccess journal that focuses on the optimal treatment of infection (bacterial, fungal and viral) and the development and institution of preventive strategies to minimize the development and spread of resistance. The journal is specifically concerned with the epidemiology of

\section{Dovepress}

antibiotic resistance and the mechanisms of resistance development and diffusion in both hospitals and the community. The manuscript management system is completely online and includes a very quick and fair peerreview system, which is all easy to use. Visit http://www.dovepress.com/ testimonials.php to read real quotes from published authors. 